\title{
AÇÕES DE EDUCAÇÃO AMBIENTAL EM ESCOLAS DO NORDESTE PARAENSE
}

\author{
Elias Fernandes de Medeiros Junior ${ }^{1}$ \\ Bruno José Corecha Fernandes Eiras ${ }^{2}$ \\ Maria José Lopes da Silva ${ }^{3}$ \\ Marileide Moraes Alves ${ }^{4}$
}

Resumo: Esta pesquisa desenvolveu-se em duas escolas localizadas no nordeste paraense, e teve como objetivo difundir as atividades do Programa de Educação Tutorial do curso de Engenharia de Pesca (PET-PESCA). As escolas foram selecionadas de forma aleatória levando-se em consideração o contexto de estarem localizadas em uma área de Reserva Extrativista (RESEX). As ações foram realizadas por meio de apresentação de palestras, discussão do tema através da interação com os alunos e apresentação de teatro de fantoches. É preciso que haja uma parceria das escolas com os órgãos ambientais competentes para a implementação de um programa de Educação Ambiental, que possa esclarecer aos alunos a importância da conservação ambiental.

Palavras-chave: Bragança; Educação Ambiental; PET-Pesca; Resex.

\footnotetext{
${ }^{1}$ Docente do Instituto Federal de Educação, Ciência e Tecnologia do Amazonas, Campus São Gabriel da Cachoeira. Mestrando em Aquicultura e Recursos Aquáticos Tropicais na Universidade Federal Rural da Amazônia. Campus Belém. E-mail: elias.aqrat@gmail.com; tj juniior@yahoo.com.br

${ }^{2}$ Mestrando do Programa de Pós-Graduação em Ciência Animal na Universidade Federal do Pará. Campus Belém. E-mail: bruno_eiras@hotmail.com

${ }^{3}$ Graduanda em Licenciatura Plena em História. Universidade Federal do Pará. Campus Bragança E-mail: maryufpa2011@gmail.com

.$^{4}$ Docente da Faculdade de Engenharia de Pesca na Universidade Federal do Pará. Campus Bragança. Email: malves@ufpa.br
}

revista brasileira educação ambiental 


\section{Introdução}

A educação constitui-se na mais poderosa de todas as ferramentas de intervenção no mundo para a construção de novos conceitos e consequentemente mudanças de hábitos (CHALITA, 2002). Com base nesse preceito a Educação Ambiental é uma estratégia de ensino que tem por objetivo conscientizar a sociedade, no intuito, de promover o desenvolvimento sustentável. A principal atribuição da Educação Ambiental é formar cidadãos que possam desenvolver um pensamento crítico a respeito da preservação ambiental e agir, de forma responsável, respeitando o meio ambiente o qual se encontra a biosfera e toda a diversidade de vida (RÊGO, 2011). Ela é um componente essencial e permanente da educação nacional brasileira, devido estar presente, de forma articulada, em todos os níveis e modalidades do processo educativo, em caráter formal e não formal (BRASIL, 1999).

Cuba (2010) relatou que a Educação Ambiental no âmbito escolar deveria ser desenvolvida como científica, ou seja, deveria ser uma disciplina que atuasse separadamente de outras, pois nos dias atuais é tratada como uma tema transversal e na maioria das vezes torna-se esquecida, devido ao fato de os educadores ficarem presos aos conteúdos que lhes são estabelecidos e que na maioria das vezes são tão extensos que os mesmos não conseguem concluí-los no final do ano letivo, e muitos professores não sentem-se na obrigação de ministrar uma tema transversal, embora este seja de extrema importância.

O principal desafio do professor do século XXI, principalmente aqueles que atuam na educação infantil e na educação de jovens e adultos seria o de construir junto com seus alunos um pensamento reflexivo sobre a necessidade de conservação do meio ambiente. Os docentes que atuam na Educação Ambiental poderiam usar diversas ferramentas como vídeos, teatro, fantoches, reciclagem e outras metodologias para desenvolverem a aprendizagem de seus alunos. A metodologia da utilização de vídeos nas escolas constitui-se um fator preponderante para o aprendizado e para a divulgação de vivências práticas, para uma maior sensibilização dos estudantes (ALBUQUERQUE, 2014). O teatro de fantoches é apontado pelos pesquisadores Dantas et al. (2012), como um recurso didático lúdico, facilmente assimilável pelas crianças da educação infantil.

A principal dificuldade em estabelecer mecanismos de intervenção ambiental em comunidades rurais, especialmente as localizadas em regiões pesqueiras, deve-se a carência de informações ambientais pelas populações que vivem nesse meio. $O$ conhecimento dessas práticas auxiliaria esses grupos na prática de desenvolvimento sustentável. Aliada a essas carências o educador tem que atuar, respeitando os preceitos já consagrados pelos moradores, ou seja, o modo de vida dessas populações, suas tradições e crenças. Temos, portanto, duas situações: a natureza fornecendo, alimentação, moradia, transporte fluvial entre outros benefícios, por outro, temos as necessidades humanas que precisam serem satisfeitas mesmo em detrimento das condições 
ambientais. De acordo com Pereira (2008), as pesquisas em Educação Ambiental deveriam considerar a constituição do sujeito pela sua cultura, sua produção local e o modo como se reproduzem socialmente.

Sendo assim as práticas de educação não formal constituem-se como ferramentas importantíssimas que poderiam ser aliadas das atividades de Educação Ambiental, haja vista, que essa, pode ocorrer nos ambientes escolares, e também em outros locais que a pratiquem. Para Aliardi et al. (2012) um dos maiores objetivos da educação não formal é a construção de novos valores, reunindo pessoas e grupos diferentes com metas em comum.

O presente trabalho teve como objetivo contribuir para o aprendizado de crianças, jovens e adultos, em questões relacionadas a conservação do meio ambiente, uma vez que as escolas onde estudam estão inseridas em municípios ricos em biodiversidade e que são áreas de preservação ambiental constituídas de Área de Proteção Ambiental APA ou Reservas Extrativistas Marinhas RESEX como as localizadas em Bragança e Augusto Corrêa ambas no Estado do Pará.

\section{Metodologia}

Participaram desse estudo os alunos do curso de Engenharia de Pesca e do Programa de Educação Tutorial do curso de Engenharia de Pesca (PET Pesca), ambos pertencentes a Universidade Federal do Pará Campus Bragança. O trabalho foi realizado em duas escolas municipais em diferentes municípios, a primeira escola está localizada na cidade de Augusto Corrêa e a segunda em Bragança, ambas no Estado do Pará. Os centros de ensino estão inseridos no contexto amazônico e a população das referidas cidades são em maioria dependentes da pesca artesanal ou residem nas proximidades de rios, retirando seu sustento da agricultura ou da pesca.

O centro de ensino André Alves é uma escola estadual de ensino fundamental e médio, localizada na vila de Nova Olinda no município de Augusto Corrêa. A escola municipal Simpliciano Fernandes encontra-se localizada na área urbana da cidade de Bragança, a escola passou por reformas ganhando novas estruturas de aprendizado e uma biblioteca com acervos atualizados. O corpo docente é formado em sua maioria por profissionais da educação Pedagogos licenciados, o centro de ensino oferece educação básica trabalhando a educação infantil pré-escola, ensino fundamental nas séries iniciais e a educação de jovens e adultos ensino fundamental séries iniciais no período noturno.

As escolas estão inseridas em municípios que possuem unidades de conservação, tais como, a Reserva Extrativista Marinha de Caeté-Taperaçú (Figura 1) que é uma unidade de conservação Federal de uso sustentável, localizada no município de Bragança Pará (BRASIL, 2005), e a Reserva Extrativista Marinha de Araí-Peroba (Figura 2), no município de Augusto Corrêa, 
Estado do Pará. Ambas as unidades de conservação têm como objetivo proteger os meios de vida e garantir a utilização e a conservação dos recursos naturais renováveis, tradicionalmente utilizados pela população extrativista residentes na área de sua abrangência (BRASIL, 2005).

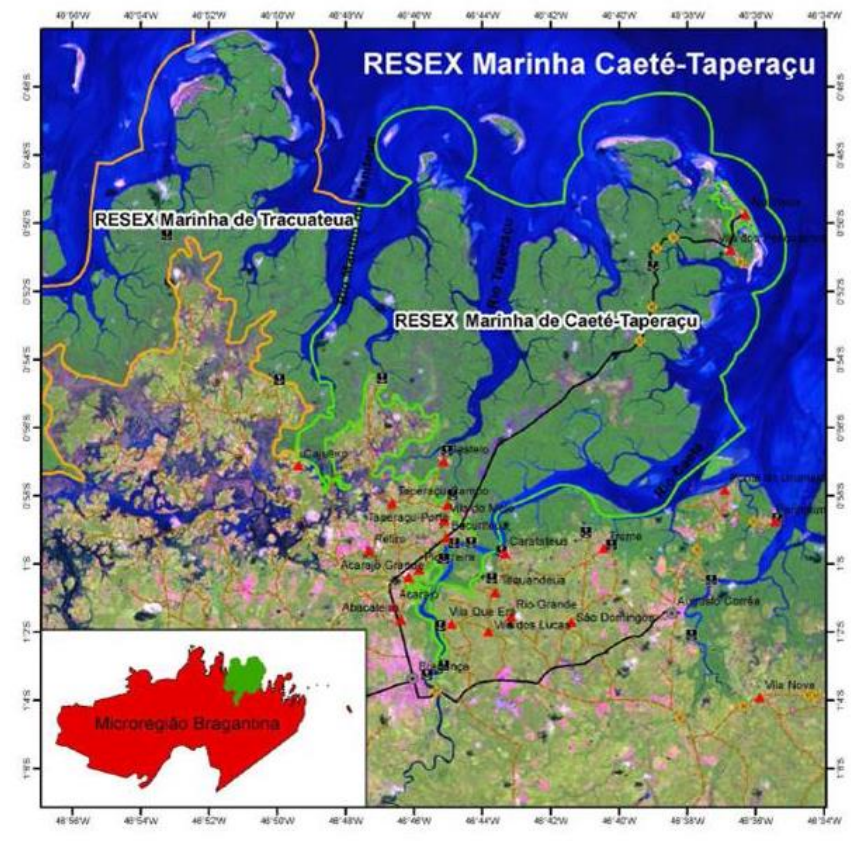

Figura 1: Reserva marinha Caeté-Taperaçu. Extraído de Plano de Manejo da Reserva Extrativista Marinha de Caeté-Taperaçu (PA), volume I.

Fonte: ECOOIDEIA.

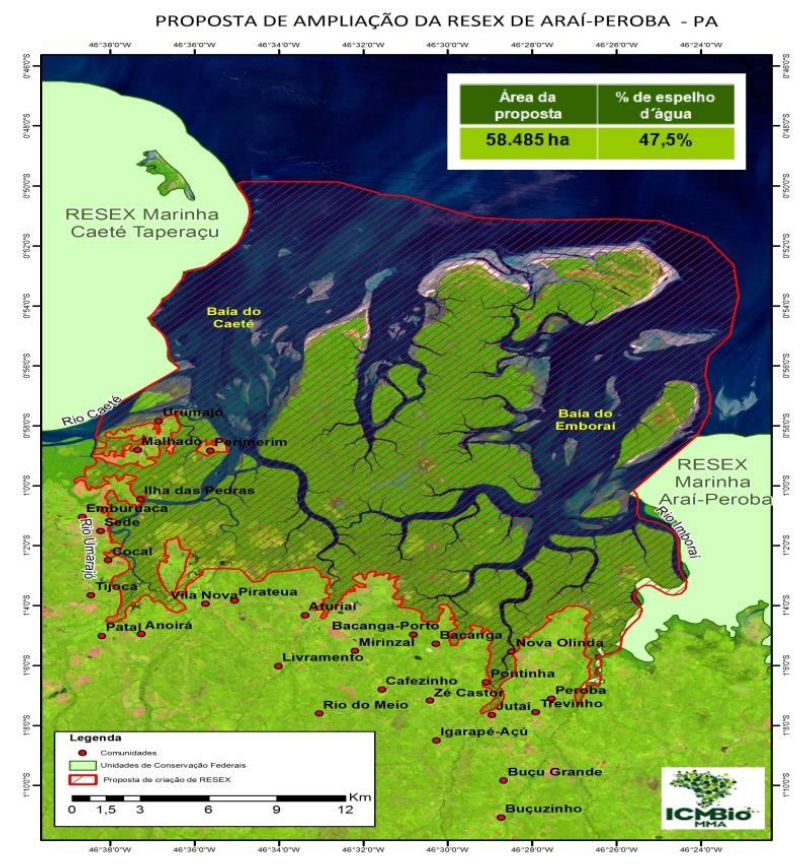

Figura 2: Reserva Marinha Araí-Peroba, localizada em Augusto Corrêa, PA. Extraído de Instituto Chico Mendes de Conservação da Biodiversidade.

Fonte: ICMBIO.

\section{Procedimento de ensino}

Na escola André Alves desenvolveu-se atividades lúdicas que consistiram primeiramente em uma palestra através de interação com os alunos, com aproximadamente cinquenta crianças na faixa etária de cinco a doze anos, onde o tema proposto foi "Meio ambiente, para quê conservar?". Para enfatizar o conteúdo e construir nas crianças o papel de conservadores do meio em que vivem a letra da música Aquarela do compositor toquinho Vinicius de Moraes foi discutida em forma de vídeo. O segundo momento de ação foi marcado pelo teatro de fantoches também abordando questões sobre o meio ambiente.

$\mathrm{Na}$ escola Simpliciano Fernandes o público alvo eram os alunos das turmas de Educação de Jovens e Adultos (EJA) do período noturno (Figura 3). Como se tratava de pessoas adultas optou-se por trabalhar o conteúdo ambiental em forma de palestra cujo tema tratado foi "Como você olha o meio ambiente, Rio Cereja um caso particular?". Três turmas de diferentes etapas de ensino 
foram concentradas em uma única sala organizada em circulo para debatermos sobre o assunto da palestra.

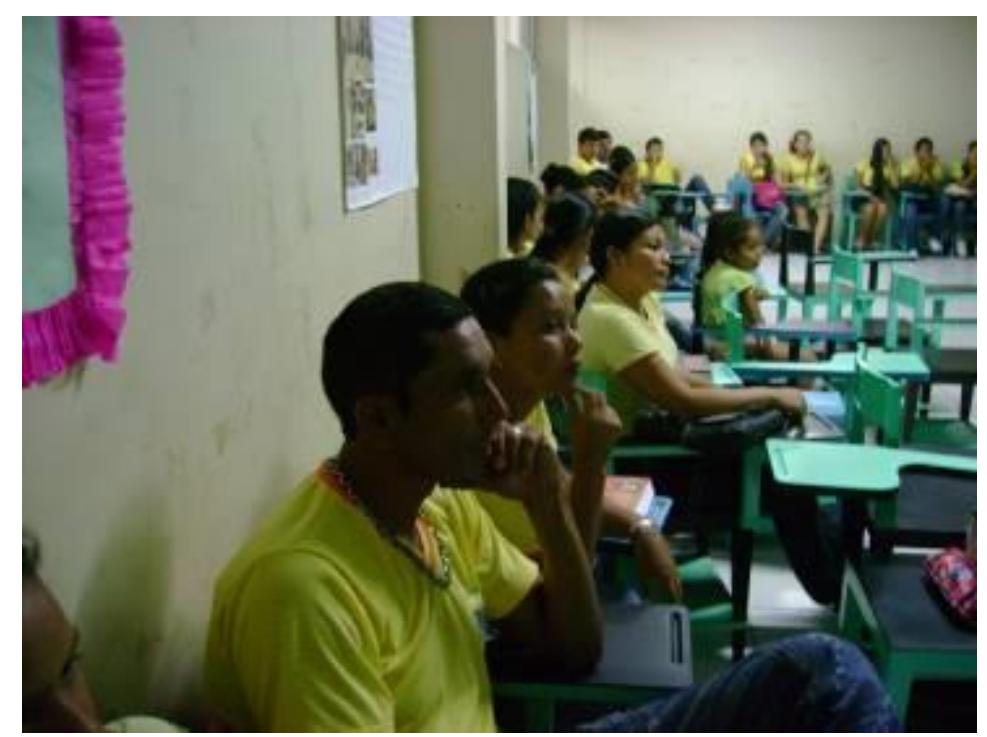

Figura 3: Alunos da turma de Educação de Jovens e Adultos (EJA) da escola Simpliciano Fernandes, participando da ação sobre meio ambiente. Fonte: Autores.

\section{Resultados e Discussão}

A construção da Educação Ambiental em escolas, deve partir da necessidade das comunidades envolvidas. $\mathrm{Na}$ área urbana deve-se pensar em mecanismos de intervenção que mostrem aos alunos a necessidade de conservação das áreas ainda restantes dos recursos naturais presentes.

Trabalhar conservação ambiental em áreas urbanas está longe de ser uma tarefa fácil, haja vista que o nível de consumo das populações urbanas é significativamente maior do que as rurais. Ao passo que nas cidades localizadas no interior do estado a população é ligeiramente menor, assim como, a área territorial explorada, o que permite ainda que com dificuldades gerenciar os ecossitemas presentes nesses municípios e tratar sobre Educação Ambiental com o foco de despertar nos discentes a importância da preservação.

No trabalho desenvolvido por Santos et al. (2012), os autores apontaram que a maioria dos professores insere a Educação Ambiental nos conteúdos programáticos, demostrando interesse e vontadde de realizar um bom trabalho. No entanto, os professores não tem um visão holística sobre o meio ambiente, pois o vem somente como o natural. Visão essa muito próxima a dos alunos que atribuem ao meio uma visão mais naturalista, a qual o autor atribui a influência da mídia televisiva.

Professores e alunos devem ser formados no intuito de entenderem que o meio ambiente não é somente o natural, mais sim tudo aquilo que faz parte de 
nosso convívio social, seja a área urbana de uma cidade, uma floresta em recuperação, a própria escola e seu espaço de convivência. Situações como estas foram enfatizadas em nossas apresentações, contribuindo para que os alunos tivessem a compreensão de como o meio ambiente está organizado e quem são os atores envolvidos em sua dinâmica.

Para Sorrentino et al.(2005), a Educação Ambiental nasce como um processo educativo que conduz a um saber ambiental materializado nos valores éticos e nas regras políticas de convívio social e de mercado, que implica a questão distributiva entre benefícios e prejuízos da apropriação e do uso da natureza.

As atividades desenvolvidas nesse trabalho, assim como, os temas tratados decorreram em função das escolas estarem localizadas em municípios dependentes das atividades pesqueiras ou por estarem nas proximidades de recursos hídricos. A escola Simpliciano Fernandes encontra-se localizada nas proximidades do rio Cereja, esse recurso hídrico desloca-se em praticamente toda a cidade de Bragança Pará. No entanto, nos últimos anos esse rio tem apresentado sérios problemas causados pela urbanização desenfreada que ocorre em suas margens, essa ocupação desenfreada e irracional pelos moradores contribuiu para a degradação do manancial, já que os proprietários das casas passaram a jogar lixos e dejetos domésticos no córrego tornando a água imprópria para consumo.

No trabalho desenvolvido por Iglesias et al. (2006), ficou constatado que a ocupação das margens do rio Cereja decorreram em função da necessidade de moradia e pela falta de políticas habitacionais no município de Bragança, dessa maneira a população passou a construir habitações sobre as margens do rio para serem usadas como moradia, e associado a isso contruiram também sanitários a céu aberto, despejando todos os dejetos fecais no córrego. Trabalhando a Educação Ambiental com as crianças e adultos Iglesias et al. (2006), obtiveram bons resultados, pois as crianças estão repassando o conhecimento adquirido para os pais, colegas e vizinhos sobre a importância da recuperação do rio Cereja.

Os alunos da turma de EJA da escola Simpliciano mostraram que têm consciência das ações realizadas pelos moradores, pois um número significativo de discentes tem suas casas próximas do rio e conhecem bem a realidade. Alguns alunos demostraram participação ao longo da palestra afirmando que procuram desenvolver a cidadania, não jogando lixo no rio e também tentam ainda que com dificuldades concientizarem seus vizinhos. A preocupação dos alunos mostrou-se ainda maior quando foi exibida algumas imagens em um dos trechos do rio que foi completamente carreado durante o período chuvoso. Observou-se que os alunos desconheciam esse fato e mostraram preocupação com a possível ocorrência de eventos como esses em áreas próximas as suas casas. 
A realidade encontrada na escola André Alves em Augusto Corrêa, é diferente da encontrada na escola Simpliciano em Bragança, devido a escola não estar nas proximidades de rios, porém, o objetivo central da ação na citada escola foi a de promover a Educação Ambiental nas crianças e adolescentes no sentido de reaproveitar materiais inorgânicos como garrafas pet, na contrução de brinquedos e artefatos que poderiam ser usadas no dia a dia, evitando dessa forma, o descarte irregular desses materiais no meio ambiente. Principalmente por não haver coleta seletiva de lixo na comunidade onde a escola encontra-se localizada, e os moradores tem como rotina jogarem seus lixos em áreas desmatadas ou controem aberturas na terra para depositarem seus lixos, contribuindo para a poluição da terra e das águas subterrâneas.

As crianças foram o público alvo na escola André Alves, dessa forma, demostrou-se que é possível realizar o aproveitamento de materiais inorgânicos em utensílios que podem serem usados cotidianamente. Tornquist et al. (2013), desenvolvolveram diversas atividades de cunho ambiental na escola EMEF José de Anchieta tais como: palestras, visitas a empresas, aulas teóricas e práticas, confecção de cartazes, painéis e peças de artesanato. Os autores obervaram que faltava á população local a conscientização quanto ao correto destino de seus resíduos.

Ao final da primeira atividade foram entregues aos meninos e meninas um desenho com enfoque ambiental envolto em tampa de refrigerante, uma espécie de canudo de diploma. O teatro de fantoches foi contruído a partir de materiais reaproveitáveis como caixas de leite líquido que viraram personagens da peça teatral que foram expostas as crianças. A participação dos alunos por meio de perguntas e respostas feitas pelos personagens da peça sobre o tema meio ambiente foi premiada com brinquedos e utilitários feito de garrafa pet, tais como: porta canetas, vai-e-vem, e porta objetos ( Figura 4).

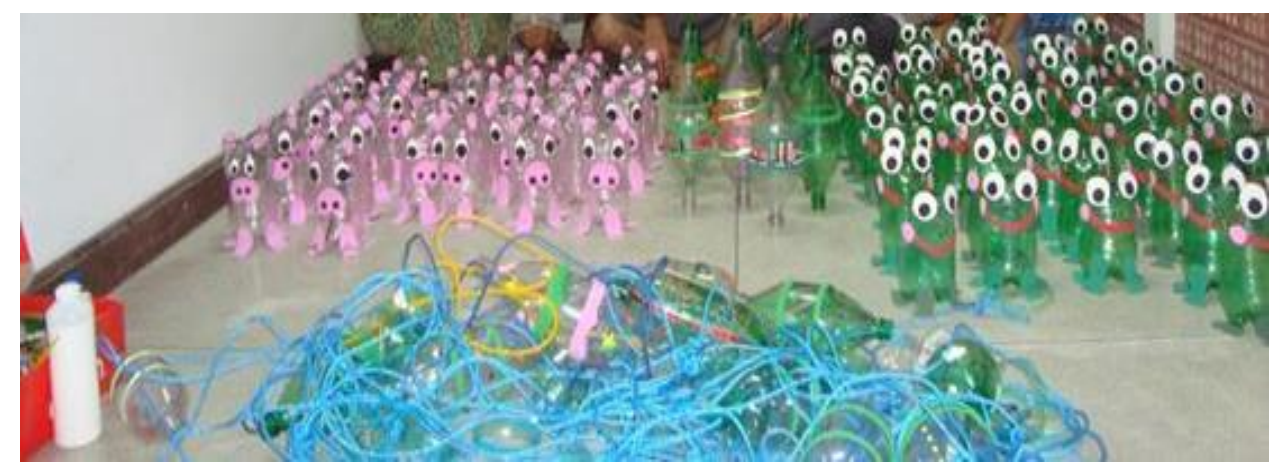

Figura 4: Brinquedos e utilitários feitos com garrafas pet, pelos alunos de Engenharia de Pesca e do Grupo PET-Pesca.

Após o encerramento das atividades realizou-se uma reunião com os pais e professores dos alunos da escola André Alves para saber a opinião deles sobre 
as atividades desenvolvidas pelo grupo Pet-Pesca. Eles mostraram-se satisfeitos com os trabalhos desenvolvidos e solicitaram ao grupo, que mantivesse sempre presente na escola realizando novas atividades de cunho educativo ambiental. As turmas de EJA da escola Simpliciano Fernandes aprovaram a iniciativa dos alunos de Engenharia de Pesca, especialmente pelo motivo de trazer ao discurso um tema recorrente no dia a dia dos moradores.

\section{Considerações Finais}

Esse trabalho mostrou a necessidade de desenvolver a Educação Ambiental nas escolas que estão localizadas em áreas de preservação ambiental. É de suma importância que os órgãos envolvidos na proteção da natureza, articulem-se com os gestores municipais na tentativa de planejar uma didática ambiental que considere a existência de áreas de proteção no município e com isso esclarecer aos pais, alunos e professores, o porque da existência de uma unidade de conservação em sua cidade. Seja através de excursões, palestras, oficinas entre outras atividades de caráter informativo.

\section{AGRADECIMENTOS}

A Universidade Federal do Pará-Campus Bragança e ao grupo PETPesca e todos seus membros. E as escolas Simpliciano Fernandes e André Alves pelo apoio durante a realização das atividades.

\section{REFERÊNCIAS}

ALBUQUERQUE, E.F. Produção de Recurso Audiovisual, como ferramenta pedagógica na Educação Ambiental aplicada. Educação Ambiental em Ação no 48, Ano XIII, Junho-Agosto, 2014.

ALIARDI, R.T; WESTERMANN, L. Educação no campo: integração entre escola e comunidade. Revista Modelos-Facos/CNEC Osório, Ano 2- vol. 2, Agosto, 2012.

BRASIL. Decreto de 20 de maio de 2005. Dispõe sobre a criação da Reserva Extrativista Marinha de Araí-Peroba, no município de Augusto Corrêa, no Estado do Pará, e dá outras providências. Brasília, DF, 2005.

BRASIL. Decreto de 20 de maio de 2005. Dispõe sobre a criação da Reserva Extrativista Marinha de Caeté-Taperaçu, no Município de Bragança, no Estado do Pará, e dá outras providências. Brasília, DF, 2005.

BRASIL. Ministério do Meio Ambiente. Lei n. 9795/1999. Dispõe sobre a Educação Ambiental, institui a Política Nacional de Educação Ambiental e dá outras providências.

CHALITA, G. Educação: a solução está no afeto. São Paulo: Gente, 2002. 
CUBA, M.A. Educação Ambiental nas escolas. ECCOM, v.1, n. 2. 2010.

DANTAS, O.M.S; SANTANA, A.R; NAKAYAMA, L. Teatro de fantoches na formação continuada docente em Educação Ambiental. Educação e Pesquisa, São Paulo, v. 38, n.03, p.711-726, jul/set 2012.

IGLESIAS, A.G; MACIEL, F.L.S; BRITO, M.R; GOMES, M.L.A recuperação do rio Cereja junto as escolas que o margeiam em Bragança Pará. II Fórum Ambiental da Alta Paulista, 2006.

PEREIRA, M.O.R. Educação Ambiental com pescadores artesanais. Práxis Educativa, Ponta Grossa, PR, V. 3, n.1, p; 73-80, jan-jun. 2008.

RÊGO, A.C.F. Educação Ambiental para Adultos. Revista Ambiente \& Educação, v. 16 (2), 2011.

SANTOS, A.A.M; BENTO, J.S. A percepção Ambiental dos Professores e Alunos da Educação de Jovens e Adultos. CIENTEC. Revista de Ciência, Tecnologia e Humanidade do IFPE- V.4, n.1. Julho de 2012.

SORRENTINO, M; TRAIBER, R; MENDONÇA, P; FERRANO JUNIOR, L.A. Educação Ambiental como política pública. Educação e Pesquisa, São Paulo, v. 31, n.2, p.285-299, maio/ago. 2005.

TORNQUIST, A; BECKER, C; SIMMIANER, J; PREUSS, L. Projeto Materiais Recicláveis: Um relato de Prática em Educação Ambiental. Revbea, Rio Grande, v.8, no 2, 2013. 